\title{
Implementasi Atribut Local Preference di Protokol BGP Untuk Optimalisasi Jaringan Backbone
}

\author{
Bambang Wijonarko ${ }^{1}$, Andi Taufik ${ }^{2}$, Irwan Pratama Aprilianto ${ }^{3}$ \\ ${ }^{1}$ Teknologi Komputer/Universitas Bina Sarana Informatika \\ e-mail: bambang.bwo@bsi.ac.id \\ ${ }^{2}$ Sistem Informasi/STMIK Nusa Mandiri \\ e-mail: a.taufik30@gmail.com \\ ${ }^{3}$ Teknik Informatika/STMIK Nusa Mandiri \\ e-mail: irwanpra1204@nusamandiri.ac.id
}

\begin{abstract}
Cara Sitasi: Wijonarko, B., Taufik , A., \& Aprilianto, I. P. (2019). Implementasi Atribut Local Preference di Protokol BGP Untuk Optimalisasi Jaringan Backbone. Jurnal Teknik Komputer, 35-42. doi:10.31294/jtk.v5i1.4792
\end{abstract}

\begin{abstract}
In terms of Nework, Network Quality determine by some factor and one of the factor is come from a Backbone Network, when traffic data exchange is occuring there are two type of path that pass by data package which we call as Downstream and Upstream Path. Every interface that build in network computer hardware usually are supported by full duplex sistem therefore in one interface it could be pass by Upstream and Downstream Data Package at the same time. When configuring both of the path, the parameter should be adjusted or else there would be an invalid routing configuration, this state would impact in network quality. iBGP Routing would help Network Administrator to set the path based on parameter adjustment in iBGP routing protocol. There are some parameter that can be use to set the network path and one of them is call local preferences, with adjust the value on the atribute of local preference the downstream and upstream path could be manage to fit the network utilities.
\end{abstract}

Keywords: routing, iBGP, local preference, backbone

\section{PENDAHULUAN}

Kebutuhan Teknologi pada dasarnya digunakan untuk mempermudah manusia dalam berbagai kegiatan dan aktivitas. Semakin meningkatnya pengguna internet di Indonesia bandwidth yang dibutuhkan untuk keperluan customer semakin meningkat, sehingga para penyedia jasa internet ISP (Internet Service Provider) harus terus mengembangkan insfrastruktur jaringan yang sudah berjalan, dalam mengembangkan infrastruktur jaringan ada beberapa aspek yang harus diperhatikan.

Aspek yang sangat penting untuk menunjang jaringan internet sampai ke user yaitu Routing protocol, menurut (Rifai \& Supriyanto, 2017) "ada beberapa jenis Routing protocol yang banyak digunakan diantaranya OSPF dan BGP, tidak ada satupun provider internet yang bisa menjadi $100 \%$ atau tidak pernah mengalami adanya gangguan distribusi koneksi internet kearah customer". Sedangkan menurut (Hikmaturokhman, Purwanto, \& Munadi, 2010) "supaya suatu paket dapat mencapai tujuannya, diperlukan suatu peralatan untuk mengatur paket-paket tersebut agar mencapai tujuannya dengan jalan yang tersingkat. Untuk itu perlu adanya router yang fungsi utamanya adalah untuk menentukan jalur dan mengirimkan paket-paket dari suatu jaringan ke jaringan lain. Agar router dapat mengetahui jalur mana yang terbaik untuk mrngirimkan paket ke alamat yang dituju, router menggunakan peta atau tabel routing”.

Oleh karena itu untuk dapat memberikan layanan koneksi internet yang stabil dan menghindari adanya down total kearah customer, umumnya suatu provider internet memiliki dua atau lebih link pada jaringan backbone begitu juga kearah customer, salah satunya dijadikan link secondary atau backup apabila link primary sedang mengalami gangguan. 
Pada perusahaan yang sedang berkembang seperti PT Maxindo Mitra Solusi yang merupakan perusahaan yang bergerak di bidang Internet Service Provider yang berdomisili di Jakarta, jaringanya sudah tersebar di pulau jawa, sumatra, kalimantan, dan bali. Tentunya memiliki infrastruktur jaringan yang besar, serta memiliki ratusan titik backbone yang sudah menjangkau berbagai daerah. Sehingga membutuhkan jaringan backbone yang stabil dikarenakan jaringan backbone merupakan penunjang kualitas dan kuantitas koneksi untuk customer. Routing yang digunakan pada setiap backbone yaitu Border Gateway Protocol (BGP) dengan Autonomous System 38320.

Menurut (Musril, 2017) Salah satu ciri khas dan juga merupakan kekuatan dari protokol routing BGP ada pada atribut-atribut pendukungnya. Atribut-atribut yang nantinya dugunakan sebagai parameter untuk menentukan jalur terbaik untuk menuju ke suatu situs. Atribut ini juga dapat mengatur masuk dan keluarnya routing update dari router-router BGP tetangga.

PT Maxindo Mitra Solusi mempunyai banyak backbone, backbone satu dengan backbone yang lainya akan saling terhubung membentuk topologi full mesh agar saling backup dan dapat dijadikan secondary link. pada jaringan backbone yang membentuk topologi full mesh menyebabkan terjadinya link failure sehingga bisa dikatakan setiap backbone terkonfigurasi half-duplex tidak fullduplex, jalur untuk downstream dan upstream terpisah , jalur downstream melalui backup link dan upstream melalui primary link sehingga yang ditimbulkan ke customer yaitu high latency, bottle neck dan intermittent.

Menurut (Ikshanto;Nugroho, 2015) Dalam metode Top-Down Network Disain, persyaratan bahwa jaringan memiliki performa yang baik adalah dengan menganailis parameter-parameter yang ada dalam jaringan komputer seperti delay, jitter, bandwidth, utilization, paket loss dan throughput. Dalam penelitian ini parameter-parameter tersebut akan diukur untuk menentukan perform jaringan dan kemudian parameter tersebut digunakan sebagai informasi untuk mendesain ulang jaringan agar performa jaringan menjadi baik serta menghasilkan desain jaringan yang lebih terstruktur sesuai akan kebutuhan perusahaan.

Oleh karena itu, dibutuhkan konfigurasi attribute atau parameter Routing yang dapat memecahkan kendala pada jaringan backbone PT Maxindo Mitra Solusi agar koneksi internet sampai ke customer dengan stabil, terstruktur dan sistematis.
Metode yang digunakan dalam penelitian ini digunakan adalah metode System Devlopment Life Cycle (SDLC) model sekuensial linier atau sering disebut juga sebagai model waterfall (Sukamto, R. A., \& Shalahudin, 2013)

\section{Analisis}

Untuk bisa membuat simulasi perancangan jaringan ini maka dibutuhkan beberapa aplikasi dan hardware pendukung seperti, gns3 sebagai simulator jaringan, virtualbox sebagai virtualisasi mesin router mikrotik, qemu sebagai virtualisasi untuk mesin juniper router dan vnc viewer sebagai aplikasi remote ke server serta koneksi internet untuk koneksi team viewer dengan server, dan hardware yang dibutuhkan yaitu server dell sebagai media untuk melakukan simulasi, dikarenakan membutuhkan spesifikasi yang tinggi untuk mejalankan operating system Junos.

\section{Desain}

Untuk desain yang akan digunakan pada simulasi Routing ini akan menggunakan virtual mesin dengan Operating system (OS) Mikrotik pada router Backbone dan router client (CPE), sedangkan untuk Router distribusi menggunakan Operating system (OS) Junos. Selain perangkat jaringan untuk test dari customer menggunakan Operating system (OS) Windows. Area yang akan diambil untuk simulasi jaringan backbone ini yaitu area backbone PT Maxindo Mitra Solusi area Tangerang dan Jakarta Barat.

Topologi yang digunakan yaitu Topologi full mesh antar link terhubung satu sama lain dan menggunakan protokol routing iBGP, dimana customer saling terhubung melalui dua link backbone, salah satunya menjadi link backup. Dan setiap backbone terhubung dengan router distribusi dimana router distribusi ini sebagai pusat atau main core jaringan backbone.

\section{Testing}

Testing dilakukan dengan melakukan konfigurasi Routing filter dan local preference pada setiap router backbone dan distribusi yang saling terhubung dengan Routing BGP, customer sebagai media pengirim data atau trafik internet, data atau trafik internet yang di kirim oleh customer akan melewati kedua backbone dan router distribusi, pada simulasi ini penulis menggunakan software atau aplikasi network simulator yaitu GNS3.

\section{METODOLOGI PENELITIAN}

\section{Implementasi}


Untuk dapat mengimplementasikan attribute Routing filter dan local preference di Routing BGP, attribute tersebut perlu dikonfigurasi disetiap Router BGP yaitu pada setiap Backbone dengan nilai atribut local preference pada setiap protocol BGP yang sudah disesuaikan agar traffic berjalan dengan normal sehingga traffic downstream dan upstream berjalan dengan semestinya.

\section{HASIL DAN PEMBAHASAN}

Berdasarkan Permasalahan yang ada dan hasil analisa tentang kebutuhan-kebutuhan yang diperlukan maka dapat diimplementasikan dan disimulasikan melalui simulator jaringan GNS3.

\section{Sistem Jaringan berjalan}

Setelah melakukan observasi kepada supervisor PT Maxindo Mitra Solusi terdapat kendala pada jaringan backbone didaerah provinsi Banten yaitu backbone BSD dan Alamsutra. Dimana klien DIG (Damai Indah Golf) memiliki dua link , yaitu link kearah BSD sebagai jalur utama dan link kearah Alamsutra sebagai jalur cadangan atau backup. Pada saat klien akan melakukan penerimaan dan pengiriman data, paket data yang akan terkirim dan terima pada jaringan backbone terbagi menjadi dua arah, yaitu upstream melalui jalur backbone BSD sedangkan downstream melalui jalur backbone Alamsutra.

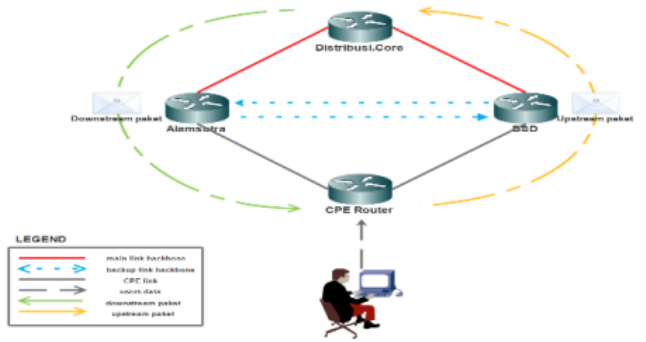

Sumber : Data Penelitian (2018)

Gambar 1. Topologi Half Duflex

Apabila upstream dan downstream tidak melalui jalur yang sama akan mengakibatkan setiap backbone hanya berjalan half-duflex dan akan mengakibatkan masalah sebagai berikut:

1. Dapat menyebabkan terjadinya bottleneck.

2. Penerimaan beban traffic pada setiap backbone tidak efisien.

3. Menyebabkan link intermittent dan high latency, atau pengiriman data tidak akan sampai dengan semestinya, aka nada paket loss ditengah perjalanan.

\section{Topologi Jaringan}

Pada jaringan Backbone yang membutuhkan performa tinggi dan downtime minimal atau bahkan tidak diperbolehkan down. Maka topologi yang digunakan yaitu full mesh.

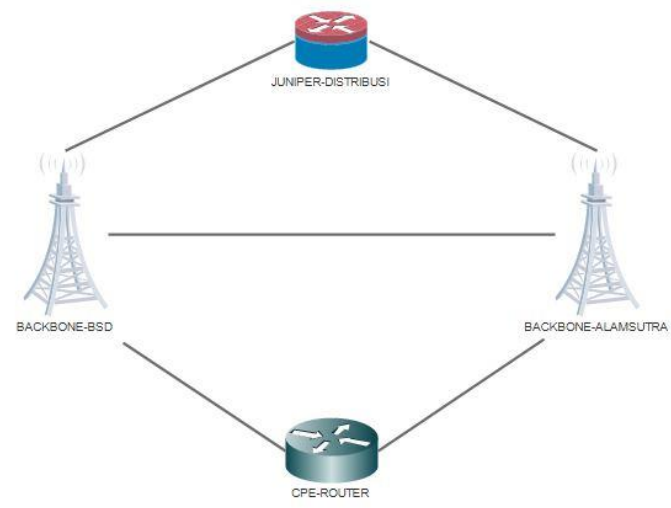

Sumber : Data Penelitian (2018)

Gambar 2. Topologi full mesh

Pada topologi mesh ini setiap perangkat bisa berkomunikasi secara langsung dengan perangkat yang dituju. Dengan memanfaatkan layer 2 pada switch Cisco topologi mesh ini bisa berjalan tanpa harus menggunakan banyak kabel atau boros kabel karena bisa menggunakan VLAN (Virtual $L A N)$

Topologi backbone PT Maxindo Mitra Solusi untuk area Provinsi Banten, yaitu backbone area BSD dan area Alamsutra. Yang dimana Backbone BSD link utama terhubung dengan Juniper Distribusi yang berada di Cyber Building Kuningan menggunakan media transmisi data fiber optic, dan backup link terhubung dengan backbone Alamsutra menggunakan media transmisi radio microwave, begitu pula dengan backbone Alamsutra. Sedangkan media transmisi yang terhubung ke klien menggunakan radio wireless.

3. Arsitektur Jaringan

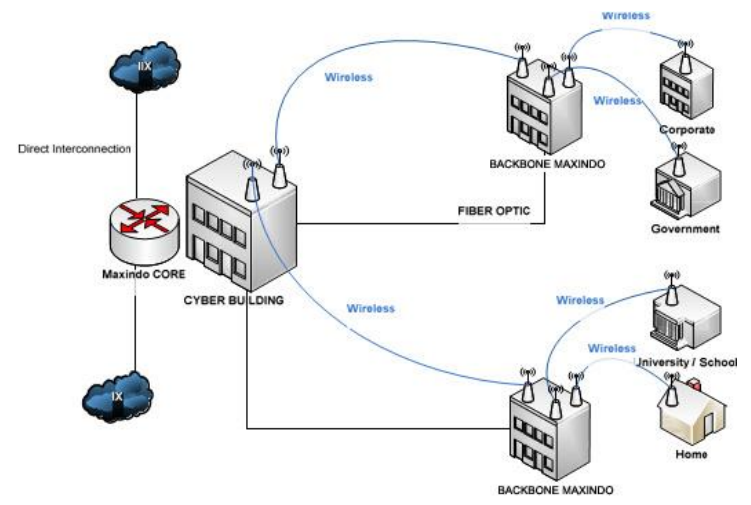

Sumber : Data Penelitian (2018)

Gambar 3. Jaringan Point to point

Pada gambar di atas dijelaskan bahwa link radio wireless dari setiap Backbone direct connect langsung ke klien. Dan pada dasarnya klien mempunyai satu link yang terhubung ke backbone, 
akan tetapi PT Maxindo Mitra Solusi fleksibel dalam menanggapi kebutuhan klien, klien tidak hanya bisa pasang satu link tetapi bisa pasang dua link yang bisa digunakan yaitu satu untuk primary link dan satu untuk backup link, untuk antisipasi apabila primary link mengalami gangguan. Selain menggunakan radio wireless klien juga bisa menggunakan media transmisi lain seperti fiber optic apabila bandwidth yang dibutuhkan besar dan di atas $50 \mathrm{Mbps}$.

Pengalamatan IP public pada klien dibedakan dalam beberapa grup yaitu IP public perusahaan, IP public game center, IP public personal dan IP public hotel. Masing-masing klien defaultnya mendapatkan satu buah IP public, setiap backbone mendistribusikan segment IP public kelas $\mathrm{C}$ yang dibagi menjadi prefix $/ 28$ dan setiap backbone akan menjadi gateway internet setiap klien. Untuk mendapatkan IP public PT Maxindo Mitra Solusi melakukan request terlebih dahulu kepada pihak IDNIC (Indonesia Network Information Center), melalui beberapa proses seperti proses administrasi pendaftaran AS (Autonomous System) dan lain-lain. IP public yang didapatkan dari IDNIC adalah IP address kelas B contoh IP public PT Maxindo Mitra Solusi yang sudah terdaftar yaitu:

Tabel 1. IP Public PT Maxindo Mitra Solusi

\begin{tabular}{cc}
\hline IP Public & $122.144 .0 .0 / 21$ \\
\hline Netmask & 255.255 .248 .0 \\
\hline $\begin{array}{c}\text { Binary } \\
\text { Netmask }\end{array}$ & 11111111.11111111 .11111000 .00000000 \\
\hline $\begin{array}{c}\text { Jumlah host } \\
\text { yang bisa } \\
\text { dipakai }\end{array}$ & 2046 \\
\hline $\begin{array}{c}\text { Broadcast } \\
\text { address }\end{array}$ & 122.144 .7 .255 \\
\hline
\end{tabular}

Sumber : Data Penelitian (2018)

Dari table di atas menjelaskan salah satu prefix PT Maxindo Mitra Solusi. Dari prefix yang didapat yaitu $122.144 .0 .0 / 21$ bisa di pecah kembali ke beberapa subnet kecil yaitu /22, /23, /24, /28 dan yang paling kecil $/ 30$.

Sedangkan untuk pendistribusian lokal seperti ke klient meggunakan IP public dengan prefix /28 yang dipecah dari prefix /24. Pembagian prefix kepada klien setiap ISP berbeda-beda dan tidak sama dikarenakan setiap ISP memiliki kebijakan masing-masing. Berikut untuk pemecahan prefix /24 ke prefix /28.

Tabel 2. Subnetting Prefix 122.144.0.0/24 upto /28

\begin{tabular}{cc}
\hline \multicolumn{2}{c}{$122.144 .0 .0 / 24$ upto /28 } \\
\hline Subnet 1 & $122.144 .0 .0 / 28$ \\
\hline Subnet 2 & $122.144 .0 .16 / 28$ \\
\hline Subnet 3 & $122.144 .0 .32 / 28$ \\
\hline
\end{tabular}

\begin{tabular}{cc}
\hline Subnet 4 & $122.144 .0 .48 / 28$ \\
\hline Subnet 5 & $122.144 .0 .64 / 28$ \\
\hline Subnet 6 & $122.144 .0 .80 / 28$ \\
\hline Subnet 7 & $122.144 .0 .96 / 28$ \\
\hline Subnet 8 & $122.144 .0 .112 / 28$ \\
\hline Subnet 9 & $122.144 .0 .128 / 28$ \\
\hline Subnet 10 & $122.144 .0 .144 / 28$ \\
\hline Subnet 11 & $122.144 .0 .160 / 28$ \\
\hline Subnet 12 & $122.144 .0 .176 / 28$ \\
\hline Subnet 13 & $122.144 .0 .192 / 28$ \\
\hline Subnet 14 & $122.144 .0 .208 / 28$ \\
\hline Subnet 15 & $122.144 .0 .224 / 28$ \\
\hline Subnet 16 & $122.144 .0 .240 / 28$ \\
\hline
\end{tabular}

Sumber : Data Penelitian (2018)

\section{Pengattributan Protokol BGP}

Perihal dengan jalur upstream dan downstream, kedua parameter tersebut merupakan bagian dari layer 3 yaitu routing, dimana masalah ada pada atribut protokol BGP yaitu local preference dan distance. Kedua atribut tersebut harus disesuaikan dengan routing akhir atau hop paling atas, apabila terdapat dua jalur (primary link dan backup link) untuk mengatur jalur upstream maka nilai distance pada primary link di setting paling kecil dan jalur backup diberi nilai lebih besar dari primary link. Sedangkan apabila ingin mengatur jalur downstream maka atribut yang dipakai pada routing BGP adalah local preference, dengan mengatur nilai local preference pada primary link lebih besar dari backup link, dikarenakan untuk local preference nilai yang lebih besar akan menjadi prioritas dibanding dengan nilai yg lebih kecil kebalikan dari distance. Dengan mengatur kedua atribut tersebut maka primary link akan berjalan full-duplex yaitu upstream dan downstream melewati satu jalur.

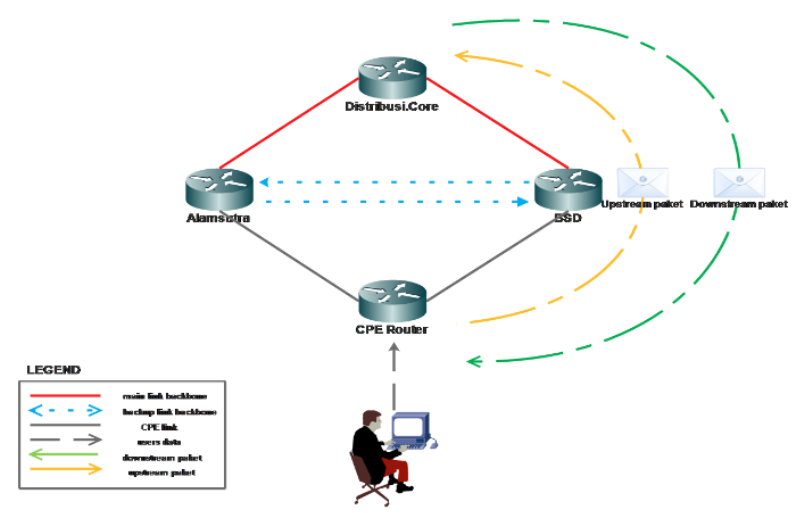

Sumber : Data Penelitian (2018)

Gambar 4. Topologi Full Duplex

Menurut ("Theresia Ghozali hal 92 100.pdf," 2015) "mengatakan bahwa dalam pemilihan jalur terbaik pada routing protocol BGP ada berbagai parameter yang diperhitungkan agar sebuah jalur dapat dikatakan sebagai jalur terbaik untuk melakukan pengiriman informasi, hal pertama 
yang diperhitungkan adalah parameter weight. Jika sebuah router memiliki dua buah atau lebih jalur alternatif untuk menuju tujuan yang sama dan memiliki nilai weight yang berbeda, BGP akan memilih rute yang memiliki nilai weight yang terbesar sebagai jalur terbaik. Namun jika dua atau beberapa jalur alternative tersebut memiliki nilai weight yang sama maka berikutknya akan dilakukan pengecekan local preference.

Nilai local preference yang besar adalah jalur terbaik jika dibandingka jalur yang memiliki nilai local preference yang kecil, namun jika beberapa jalur jalur alternative memiliki nilai local preference yang sama makan berikutkan akan dilakukan pengecekan terhadap origin. Jalur terbaik berikutnya akan dipilih jika jalur tersebut memiliki lokal origin yang sama dengan lokal origin si pengirim (IGP < EGP < incomplete) dan memiliki AS_Path terpendek, namun jika baik origin maupun AS_Path memiliki nilai yang sama maka berikutkan akan dibandingkan nilai MED”.

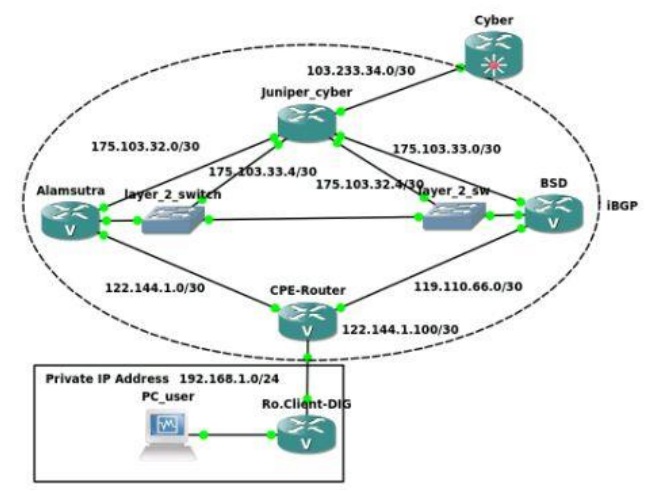

Sumber : Data Penelitian (2018)

Gambar 5. Aristektur Jaringan Backbone

Pada dasarnya setiap provider internet menggunakan dynamic routing untuk diterapkan pada setiap backbone karena pada jaringan skala besar dynamic routing itu berperan penting untuk distribusi IP address dan juga mengatur alur traffic yang lewat, tetapi dalam hal konfigurasi setiap provider akan berbeda-beda, hal tersebut disebabkan karena disesuaikan dengan kebutuhan masingmasing setiap provider. Dalam hal routing jaringan backbone PT Maxindo Mitra Solusi menerapkan iBGP (Internal Border gateway protocol).

terdapat 6 router diantaranya, router cyber, router juniper cyber, router backbone Alamsutra, router backbone $\mathrm{BSD}$, router CPE (Customer Premise Equipment) dan router client, penulis mengambil contoh kasus pada client DIG (Damai Indah Golf). Setiap router yang terinstall mempunyai peran yang berbeda, selain router terdapat Cisco switch dan personal computer.

\section{Pengujian Jaringan Awal}

Untuk pengujian awal menggunakan simulator GNS3, dengan kondisi traffic jaringan pada setiap router backbone half duflex, downstream melewati jalur backup backbone Alamsutra dan upstream melewati jalur primary BSD. Dengan parameter-parameter yang sudah disetting sebelumnya, tahan pengujian akan dilakukan pada prefix atau IP public klien, berikut konfigurasi jaringan backbone pada tahap pengujian jaringan awal:

a. Atribut local Pref pada setiap router Backbone

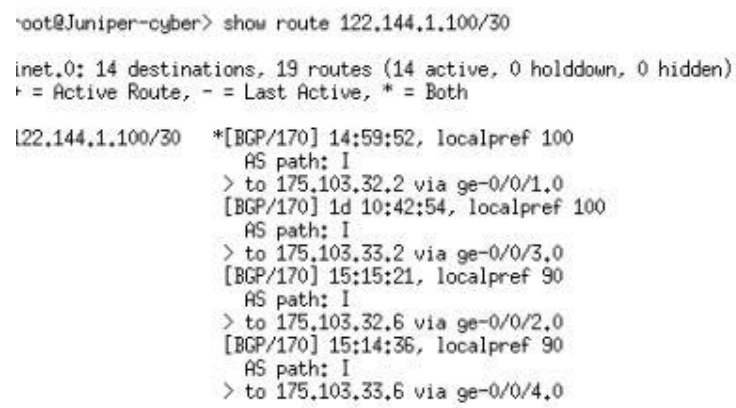

Sumber : Data Penelitian (2018)

Gambar 6. Local Preference Prefix 122.144.1.100/30

Dapat dilihat diatas Downstream atau bisa disebut juga route balik untuk IP public 122.144.1.100/30 melewati backup link Alamsutra.

b. Route distance pada router backbone dan $\mathrm{CPE}$

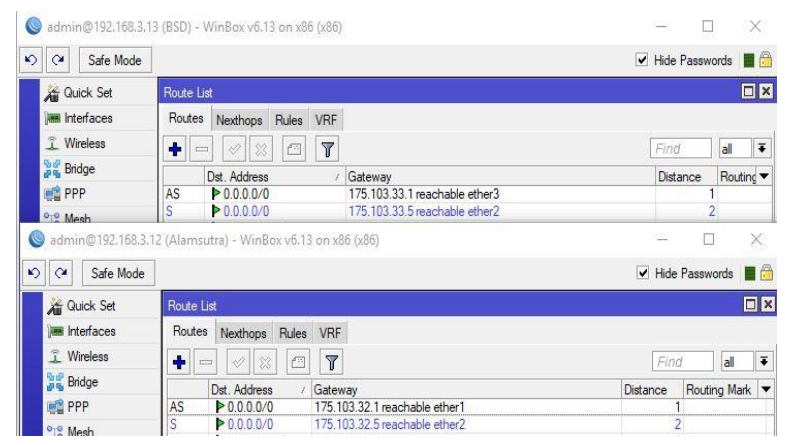

Sumber : Data Penelitian (2018)

Gambar 7. Default route backbone

Route aktif berstatus AS (Active Static) untuk router BSD primary link dengan default route 175.103.33.1 dan untuk router Alamsutra primary link dengan default route 175.103.32.1.

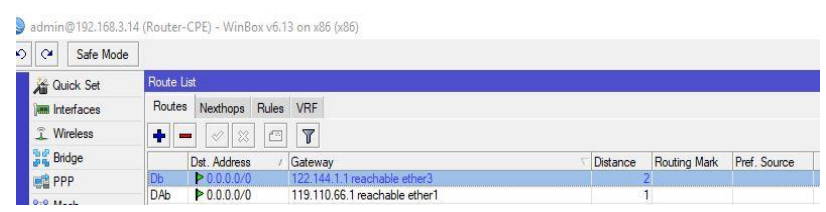

Sumber : Data Penelitian (2018) 


\section{Gambar 8. Default route $\mathrm{CPE}$}

route yang aktif dengan status DAb (Dynamic Active $B G P$ ) ada pada interface ether 1 dengan IP route 119.110.66.1 dimana IP tersebut adalah IP route untuk kearah backbone BSD dan otomatis menjadi default route klien.

\begin{tabular}{|llllll}
\hline [admin@Cyber] $>$ tool traceroute damaiindahgolf.co.id & \\
\# ADDRESS & LOSS SENT & LAST & AVG & BEST \\
1103.233 .34 .2 & $0 \% 4083$ & $0 \mathrm{~ms}$ & 2.5 & 0 & \\
2175.103 .32 .2 & $0 \% 4082$ & $10 \mathrm{~ms}$ & 8 & 0 \\
3119.110 .66 .2 & $0 \% 4082$ & $0 \mathrm{~ms}$ & 4.7 & 0 \\
4122.144 .1 .102 & $0 \% 4082$ & $10 \mathrm{~ms}$ & 9.8 & 0 \\
\hline
\end{tabular}

Sumber : Data Penelitian (2018)

Gambar 9. Traceroute balik dari router cyber kearah klien

Menjelaskan urutan jalur downstream yaitu pertama router cyber sebelum menuju ke IP address tujuan yaitu klient melewati juniper cyber dengan $I P$ address 103.233 .34 .2 , lanjut ke hop berikunya yaitu menuju jalur backbone Alamsutra dengan IP address 175.103.32.2 setelah melalui router backbone berlanjut ke IP address 119.110.66.2 yang merupakan IP address point ot point backbone Alamsutra dan CPE-router. dan terakhir sampai di IP address tujuan yaitu IP public klien 122.144.1.102.

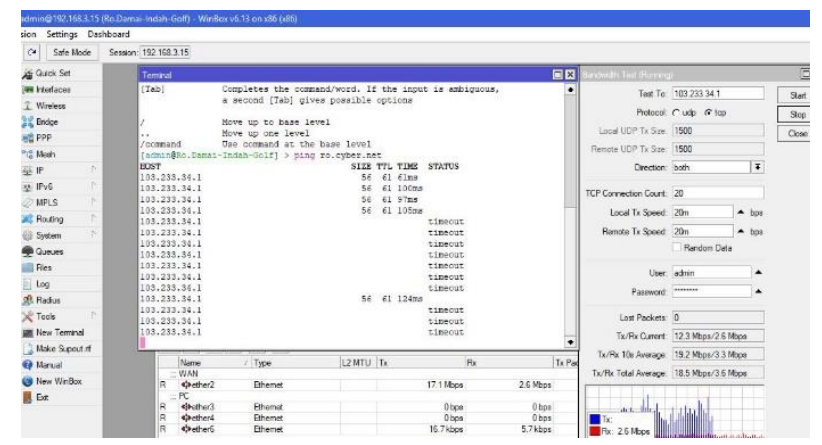

Sumber : Data Penelitian (2018)

Gambar 10. Intermittent dan High Latency

Hasil ping dari router klien ke arah cyber menunjukan latency tinggi dan terdapat banyak paket loss dikarenakan jalur backbone yang dilewati memiliki kapasitas bandwidth tidak sesuai dan tidak full duplex.

\section{c. Bandwidth test dari Mikrotik klien}

Setelah melakukan pengujian dari segi ping dan traceroute, dengan tujuan memastikan pengujian dari hasil routing iBGP yang berjalan, dilakukan pengujian bandwidth yang diterima oleh masing-masing backbone. Berikut hasil pengujian bandwidth test yang diuji pada simulasi:

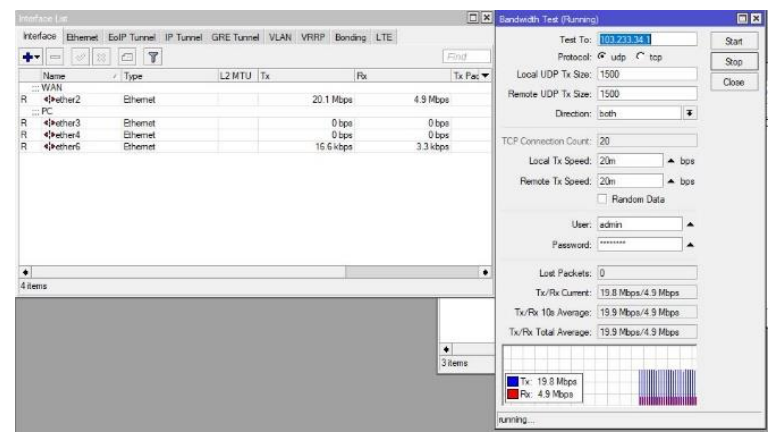

Sumber : Data Penelitian (2018)

Gambar 11. Bandwidth test dari klien kearah cyber

Pengujian dilakukan dengan pengiriman traffic protokol UDP dengan besaran paket data yang dikirim 20Mbps, dan tertera pada gambar hasil dari pengujian bandwidth test traffic upload yang lewat bisa sampai 20Mbps sedangkan download hanya dapat 4.9Mbps dan menyebabkan bottleneck.

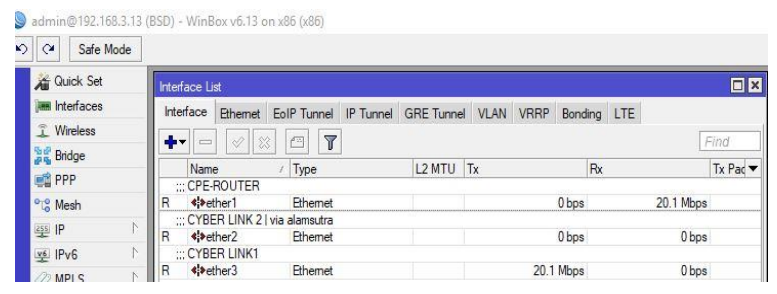

Sumber : Datal Penelitian (2018)

Gambar 12. Traffic UDP yang melalui router backbone BSD

Pada gambar diatas hanya upstreamnya saja dengan besaran bandwidth 20Mbps sedangkan untuk downstream besaran bandwidth $0 \mathrm{bps}$.

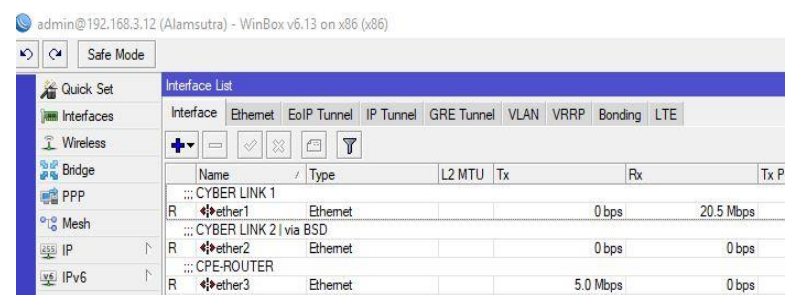

Sumber : Data Penelitian (2018)

Gambar 13. Pengecekan traffic yang lewat melalui jalur backbone Alamsutra

Besaran bandwidth download yang bisa lewat melalui interface router hanya $5 \mathrm{Mbps}$ sedangkan untuk interface kearah cyber bisa mencapai 20Mbps bisa di katakan bahwa jalur download yang melewati backbone Alamsutra mengalami bottle neck

6. Pengujian Jaringan Akhir 
Pada pembahasan pengujian jaringan awal bahwa ada perbedaan jalur pada upstream dan downstream. Hal tersebut dikarenakan nilai local preference yang sama di antara link primary kedua backbone, nilai local preference primary link backbone BSD 100 dan begitu pula dengan primary link Alamsutra mempunyai nilai sama 100. Sehingga apabila terbaca dengan nilai yang sama jalur akan di baca random atau dibaca sesuai dengan routing yang diberikan dengan nilai IP address next-hop paling kecil, dan pada simulasi ini nilai IP address pada routing table backbone yang paling kecil adalah backbone Alamsutra yaitu 175.103.32.2 dan urutan kedua link primary BSD 175.103.33.2.

\begin{tabular}{|c|c|}
\hline $122.144 .1 .100 / 30$ & 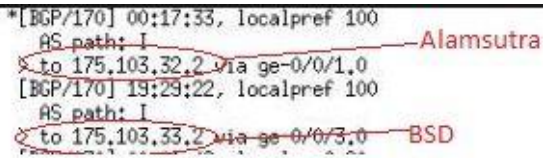 \\
\hline
\end{tabular}

Sumber : Data Penelitian (2018)

Gambar 14. Penilaian Prioritas berdasarkan IP address

IP address 175.103.32.2 menjadi prioritas dari downstream. Hal tersebut menjadi masalah pada routing jaringan backbone ini dikarenakan yang seharusnya melewati jalur full duplex backbone BSD yaitu downstream dan upstream melalui satu jalur primary link backbone BSD. Sehingga kita harus konfigurasi Local preference.

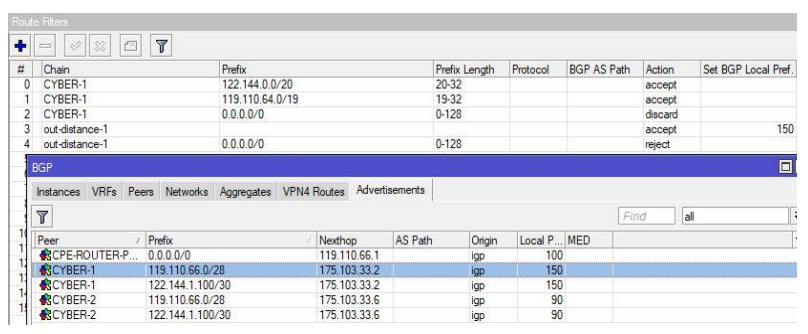

Sumber : Data Penelitian (2018)

Gambar 15. Konfigurasi local Preference router backbone

Local preference disetting pada routing filter dengan nilai 150 agar nilai lebih besar dari backbone Alamsutra yaitu 100 sehingga tertera pada gambar 18 backbone BSD melakukan advertisement prefix klien 122.144.1.100/30 dengan nilai local preference 150.

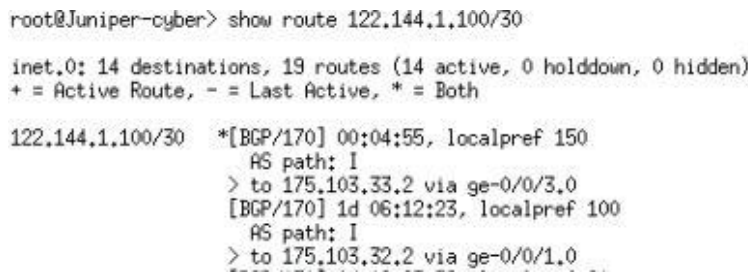

Sumber : Data Penelitian (2018)

Gambar 16. Status routing table setelah konfigurasi local preference

Pada status route di gambar tersebut menunjukan bahwa downstream IP public 122.144.1.100/30 sudah melalui jalur backbone BSD dengan nilai local preference 150 .

\begin{tabular}{|llllllllll|}
\hline [admin@Cyber] > tool traceroute damaiindahgolf.co.id & & & \\
\# ADDRESS & LOSS SENT & LAST & AVG & BEST & WORST STD-D> \\
1103.233 .34 .2 & $0 \%$ & 4 & $10 \mathrm{~ms}$ & 16.7 & 0 & 40 & $>$ \\
2175.103 .33 .2 & $0 \%$ & 3 & $0 \mathrm{~ms}$ & 3.3 & 0 & 10 & $4>$ \\
3119.110 .66 .2 & $0 \%$ & 3 & $10 \mathrm{~ms}$ & 6.7 & 0 & 10 & $4>$ \\
4122.144 .1 .102 & $0 \%$ & 3 & $10 \mathrm{~ms}$ & 10 & 10 & 10 & $>$ \\
\hline
\end{tabular}

Sumber : Data Penelitian (2018)

Gambar 17. Hasil traceroute dari router cyber kearah klien

Hasil traceroute sudah menunjukan bahwa downstream sudah melewati backbone BSD dengan IP address 175.103.33.2 dan begitu pula untuk upstream melewati jalur backbone BSD 119.110.66.1

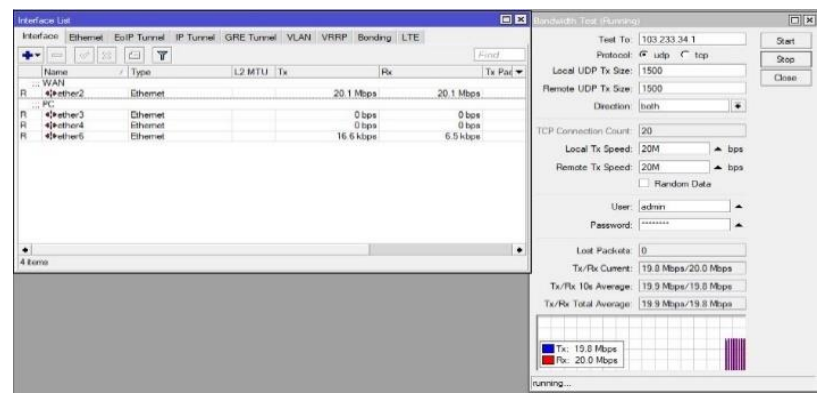

Sumber : Hasil Penelitian (2018)

Gambar 18. Pengujian bandwidth test akhir dari router DIG

Hasil akhir bandwidth yang didapatkan sesuai dengan besaran bandwidth yang diuji yaitu dedicated 20Mbps untuk upload dan download berbeda dengan pengujian awal download hanya Sebesar 4.9Mbps.

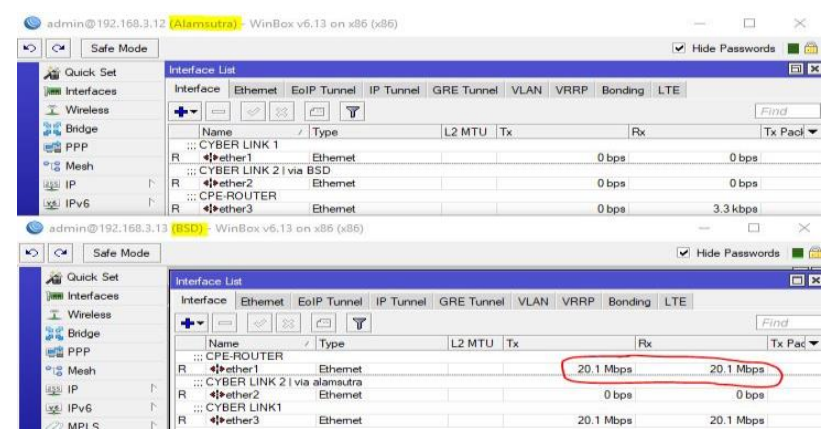

Sumber : Hasil Penelitian (2018) 
Gambar 19. Traffic yang lewat masing-masing router Backbone

Untuk fungsi dari primary link BSD sudah menjadi full duflex, downstream dan upstream sudah melewati primary link BSD dengan besaran bandwidth yang dikirim oleh klien 20Mbps sedangkan untuk router backbone Alamsutra sudah tidak dilewati traffic dan berperan sebagai passive backup.

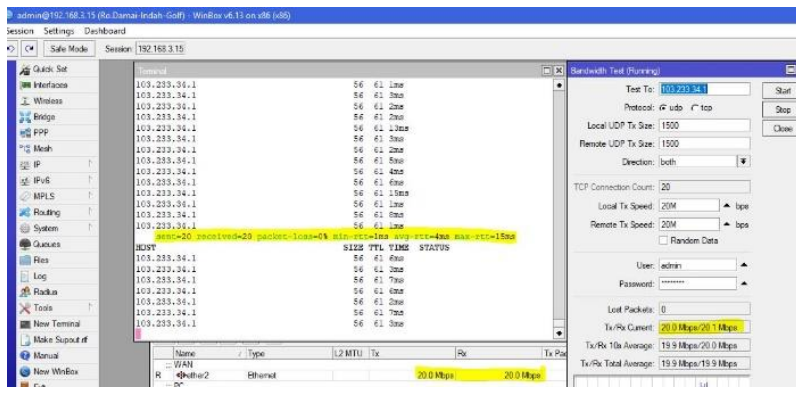

Sumber : Data Penelitian (2018)

Gambar 20. Latency ping dan pengetesan jalur dilewati bandwidth.

Pada gambar di atas menunjukan hasil link setelah konfigurasi nilai local preference pada setiap backbone dan link full duplex sudah melewati jalur backbone BSD, ping latency normal setelah dilewati beban traffic $20 \mathrm{Mb}$ yang sebelumnya ping intermittent dan terdapat banyak packet loss.

\section{KESIMPULAN}

Dalam pemaparan proses simulasi dan implementasi ini telah diuraikan konfigurasi atribut local preference pada protokol routing iBGP dan berdasarkan identifikasi masalah yang dijelaskan di atas, penulis dapat menyimpulkan bahwa:

1. Atribut local preference dapat mengatur jalur lalu lintas paket data yang akan melewati router BGP.

2. Routing pada infrastruktur backbone sangat mempengaruhi kualitas dan kuantitas jaringan internet yang akan diberikan kepada klien.

3. Atribut local preference dengan nilai yang sudah disesuaikan dengan kebutuhan setiap backbone akan memberikan kestabilan pada jaringan backbone PT Maxindo Mitra Solusi.

4. Atribut local preference yang sudah dikonfigurasi dengan benar akan memudahkan para Network Administrator melakukan maintenance atau troubleshooting.

\section{REFERENSI}

Hikmaturokhman, A., Purwanto, A., \& Munadi, R.
(2010). Analisis Perancangan Dan Implementasi Firewall Dan Traffic Filtering Menggunakan Cisco Router. Seminar Nasional Informatika, 2010(semnasIF), C1$\mathrm{C} 8$.

Ikshanto;Nugroho. (2015). Analisis Performa Dan Desain Jaringan Komputer Menggunakan Top-Down Network Desain Studi Kasus Pada Cv. Merah Putih, 01(01), 69-82.

Musril, H. A. (2017). Simulasi Interkoneksi Antara Autonomous System ( As ) Menggunakan Border Gateway Protocol ( Bgp ). Jurnal Nasional Informatika Dan Teknologi Jaringan E-ISSN:2540-7600 P-ISSN: 2540-7597, Vol 2,No 1(26181), 1-9.

Rifai, B., \& Supriyanto, E. (2017). Management System Failover Dengan Routing Dinamis Open Shortest Path First Dan Border Gateway Protocol. JITK (Jurnal Ilmu Pengetahuan Dan Teknologi Komputer), 3(1), 39-46. Retrieved from

http://ejournal.nusamandiri.ac.id/ejurnal/index. php/jitk/article/view/431

Sukamto, R. A., \& Shalahudin, M. (2013). Rekayasa Perangkat Lunak Terstruktur Dan Berorientasi Objek. Bandung: Informatika.

Theresia Ghozali hal 92 100.pdf. (2015). Media Teknika Jurnal Teknologi, 10. Retrieved from https://www.usd.ac.id/lembaga/lppm/f113/med ia teknika vol 10 2015/Theresia Ghozali hal 92 100.pdf

\section{PROFIL PENULIS}

Bambang Wijonarko M.Kom, menyelesaikan pendidikan S1 di STMIK Nusa Mandiri, jurusan Teknik Informatika dan S2 Ilmu Komputer di STMIK Nusa mandiri. Pada saat ini aktif mengajar di STMIK Nusa mandiri sebagai Dosen, minat dalam bidang Penelitian Data Mining dan Networking.

Andi Taufik M.Kom, Lahir di Bogor 30 November 1991. Lulus Sarjana 2014 dan Lulus Pasca Sarjana STMIK Nusa Mandiri tahun 2016. saat ini aktif mengajar di STMIK Nusa mandiri sebagai Dosen, minat Pada bidang Jaringan Komputer dan Data Mining.

Irwan Pratama Aprilianto S.Kom, menyelesaikan pendidikan S1 di STMIK Nusa Mandiri. bekerja di PT Maxindo Mitra Solusi sebagai NOC, tertarik dan minat pada bidang networking 